\title{
CARACTERIZAÇÃO DE GRÃOS DE CEVADA EM RELAÇÃO A UMIDADE INICIAL OBTIDA ATRAVÉS DO PROCESSO DE REUMIDIFICAÇÃO
}

\author{
G. ALBINI ${ }^{1}$, F. B. FREIRE $^{1}$, J. T. FREIRE ${ }^{1 *}$ \\ ${ }^{1}$ Universidade Federal de São Carlos, Departamento de Engenharia Química \\ e-mail: freire@ufscar.br
}

\begin{abstract}
RESUMO
O presente trabalho teve como objetivo determinar as características físicas dos grãos de cevada da variedade Cauê em relação a umidade inicial. Os parâmetros avaliados englobam a determinação da umidade, diâmetro de Sauter, dimensões, forma, massa específica e porosidade. As técnicas utilizadas para a determinação dessas características foram método da estufa, análise de imagens, picnometria líquida e gasosa, peneiramento e empacotamento do leito. Com base nos dados experimentais foi possível constatar que as características físicas do material em função da umidade apresentaram variação significativa, o que implicou em mudanças externas, apresentando, portanto, encolhimento durante a secagem.
\end{abstract}

\section{INTRODUÇÃO}

A cevada (Hordeum vulgare) é um cereal de inverno, ocupa a quinta posição de importância econômica no mundo. O grão é utilizado na produção de bebidas, como cerveja e destilados, na composição de farinhas para panificação, na produção de medicamentos e nas fórmulas de produtos dietéticos. É também utilizada como alimentação animal, forragem verde, e na fabricação de ração (BRASIL, 2013).

O armazenamento dos grãos é considerado adequado quando a umidade é inferior a $12 \%$ (base úmida). Para períodos mais longos de armazenamento, um conteúdo de umidade de $10 \%$ é o mais indicado (BRIGGS et al., 2004). Segundo Kunze (2004), quando a cevada é armazenada úmida, ela perde sua capacidade germinativa e produz um malte de má qualidade. Portanto, cevada contendo mais do que $12 \%$ de umidade deve passar pelo processo de secagem antes do armazenamento.
Em geral, a secagem é feita por técnicas térmicas e, portanto, envolve a aplicação de calor, geralmente por convecção a partir de uma corrente de ar. A troca de energia e massa entre o fluido e o sólido pode ser influenciada pela configuração do material no secador, pelas condições operacionais do secador como temperatura, velocidade e umidade do fluido, e também pelas propriedades do sólido, como umidade, temperatura, tamanho, forma, massa específica e porosidade (McMINN e MAGEE, 1999).

Com os dados das propriedades do material é possível realizar a descrição do processo de secagem, o dimensionamento de secadores, de sistemas de armazenamento e a avaliação de processos envolvendo transferência de calor.

Também é desejável conhecer como estas propriedades variam com a umidade, o que permite prever sua variação ao longo do processo de secagem.

Assim, o presente trabalho teve como objetivo determinar as características físicas 
dos grãos de cevada da variedade Cauê em função da umidade inicial. Os parâmetros avaliados englobam a determinação da umidade, diâmetro de Sauter, dimensões, forma, massa específica e porosidade.

\section{MATERIAL E MÉTODOS}

\subsection{Material e sua preparação}

O material utilizado no trabalho foram grãos de cevada (Hordeum vulgare), variedade Cauê. Os grãos foram adquiridos da Cooperativa Agrária Agroindustrial, localizada no Distrito de Entre Rios Guarapuava/Paraná. Os grãos utilizados pertenciam ao mesmo lote.

Uma vez que é difícil obter grãos recém-colhidos, os grãos adquiridos já haviam sido submetidos à secagem prévia. Assim, para obter a relação das propriedades físicas dos grãos em função da sua umidade foi feita a reumidificação dos grãos.

Os grãos foram adquiridas com umidade inicial $\left(X_{b u}\right)$ de 10\%. Em seguida, foram reumidificados em três conteúdos diferentes de umidade, $26 \%$ (X1), 21\% (X2) e $13 \%$ (X3), que foram escolhidos com base no fato que a umidade da cevada sofre variações devido a fatores climáticos, temporais e genéticos, podendo variar de $12 \%$ a $25 \%$ (KUNZE, 2004; TUNES et al., 2010).

Para verificar se o tempo após a reumidificação altera as características de cinética de secagem foram utilizados dois procedimentos para reumidificar os grãos, que chamaremos de reumidificação lenta e reumidificação rápida.

Reumidificação lenta: Uma quantidade de grãos de massa e umidade iniciais conhecidas foi colocada dentro de um pote plástico e foi adicionada a massa calculada de água, de modo que a umidade final fosse préestabelecida, através de um balanço de massa (VIEIRA, 2012). Após aproximadamente 2 horas a água adicionada foi absorvida. Os grãos foram colocados em potes e mantidos em geladeira doméstica por 24 horas para distribuição da umidade. As amostras permaneceram armazenadas em geladeira até serem utilizadas nos experimentos.

Reumidificação rápida: Também seguiu o procedimento descrito anteriormente, mas na reumidificação rápida os grãos já eram utilizados após a absorção da água, não havendo a etapa de armazenamento dos grãos em geladeira.

\subsection{Secagem em camada fina}

Neste trabalho, foi utilizado um leito delgado de $1 \mathrm{~cm}$ de espessura e diâmetro interno de $10,0 \mathrm{~cm}$ recheado com grãos de cevada (Hordeum vulgare) da variedade Cauê. A espessura do leito foi determinada em experimentos preliminares, realizados com termopares inseridos na entrada e na saída do leito que detectaram uma variação de temperatura menor do que $0,5^{\circ} \mathrm{C}$. A partir destes resultados, a espessura de $1 \mathrm{~cm}$ foi adotada como critério para o estudo da camada fina.

Os estudos de cinética de secagem foram realizados em um secador de leito fixo, onde o meio foi submetido a um escoamento monofásico e ascendente de ar em determinadas condições de velocidade, umidade e temperatura. Nos experimentos, o leito de massa inicial conhecida foi submetido ao processo de secagem e pesado em intervalos de tempo pré-estabelecidos em uma balança analítica (precisão $1 \times 10^{-3} \mathrm{~g}$ ). A massa seca foi obtida mantendo-se o meio em estufa com circulação de ar a $105 \pm 3^{\circ} \mathrm{C}$ por 24 horas. As condições operacionais nas quais os estudos de secagem foram realizados obedecem às seguintes faixas operacionais: 40 $\leq T_{g}\left({ }^{\circ} \mathrm{C}\right) \leq 50 ; 0,8 \leq v_{g}(\mathrm{~m} / \mathrm{s}) \leq 4,0 ; 2,9 \leq U R$ $(\%) \leq 26,6 ; X_{0}(\%$, base úmida $)=21,1 \pm 0,4$. A umidade relativa do ar dependeu das condições laboratoriais, e foi determinada diretamente por um termo-higrômetro. 


\subsection{Métodos para caracterização}

Determinação de umidade: A umidade dos grãos foi determinada pelo método da estuda a $105^{\circ} \mathrm{C} \pm 3{ }^{\circ} \mathrm{C}$ por 24 horas. $\mathrm{O}$ método de referência é o da AOAC (2002).

Análise Granulométrica: A análise granulométrica para determinar o diâmetro médio de Sauter $(\bar{D})$ foi realizada utilizando um agitador da marca Retsch AS 200 Control com peneiras de aberturas de malha de 4,00 $\mathrm{mm}, 3,35 \mathrm{~mm}, 2,80 \mathrm{~mm}, 2,36 \mathrm{~mm}$ e $2,00 \mathrm{~mm}$, da marca Retsch.

Com a massa de grão retida em cada peneira foram calculadas suas respectivas frações mássicas e obtida uma média de cada fração calculada, com este valor foi calculado o diâmetro médio de Sauter $(\bar{D})$ pela Equação 1 (FUMAGALLI, 2007).

$$
\bar{D}=\frac{1}{\sum_{i=1}^{n} \frac{x_{i}}{D_{i}}}
$$

Dimensões: As dimensões e a circularidade das partículas foram determinadas por análise de imagens com auxílio do software Image Pro Plus 6®. As imagens dos grãos de cevada foram obtidas com uma câmera digital Samsung com definição de 12.2 megapixels. Os grãos foram dispostos, em arranjos de $5 \times 5$ grãos (25 grãos por amostra), sobre um fundo preto com uma régua, a medida da régua foi referência para relação de pixel da imagem e medida em milímetros pelo software. Para cada umidade inicial foram realizadas análise de imagens em triplicatas.

Os parâmetros determinados pelo software foram a área projetada, o perímetro, a largura, o comprimento, espessura e a circularidade dos grãos. Obtidos os dados de comprimento (L'), largura (W), espessura (T')

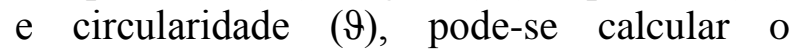
diâmetro da parte esférica (B), volume (V), área superficial (S) e esfericidade $(\phi)$ utilizando as seguintes equações (MOHSENIN, 1970):

$$
\begin{aligned}
& B=\sqrt{W \cdot T^{\prime}} \\
& V=\frac{\pi \cdot B^{2} \cdot L^{2}}{6\left(2 L^{\prime}-B\right)} \\
& S=\frac{\pi \cdot B \cdot L^{\prime 2}}{2 L^{\prime}-B} \\
& \phi=\frac{1}{\vartheta}=\frac{A_{p} 4 \pi}{P^{2}}
\end{aligned}
$$

Massa e volume de $\mathbf{1 0 0 0}$ grãos de cevada: Para cada umidade inicial, 1000 grãos de cevada foram separados e pesados, em triplicata. Logo após, utilizando uma proveta de $100 \mathrm{~mL}$, os grãos foram empacotados no leito com o auxílio de um funil para derramar os grãos no interior do recipiente (ZOTIN, 1985) e obtendo-se assim o volume ocupado.

Picnometria gasosa: A massa específica real foi determinada por picnometria gasosa a Hélio em picnômetro Ultrapycnometer 1000 Quantachrome Instruments, cujo princípio de operação baseia-se no deslocamento de gás pelo sólido (Princípio de Archimedes).

$\mathrm{O}$ equipamento foi programado para realizar 10 corridas simultâneas com a mesma amostra e ao final do processo apresentava o volume médio e a massa específica real média. Foram realizadas triplicatas para cada umidade inicial.

$$
\rho_{s}=\frac{m}{V_{s}}
$$

Picnometria líquida: A massa específica aparente foi determinada por picnometria líquida com hexano em um picnômetro previamente calibrado. Foram realizadas triplicatas para cada umidade inicial. E utilizou-se a Equação 7 para os cálculos. 


$$
\rho_{p}=\frac{m}{V_{p}}
$$

Densidade do leito (bulk): Utilizando uma proveta de $100 \mathrm{~mL}$, amostras de aproximadamente 100 gramas de grãos de cevada foram empacotadas no leito com o auxílio de um funil para derramar os grãos no interior do recipiente (ZOTIN, 1985). Através da razão entre a massa de partículas e o volume preenchido da proveta foi possível determinar a densidade volumétrica (bulk), Equação 8.

$$
\rho_{b}=\frac{m}{V_{b}}
$$

Porosidades: A porosidade da partícula $\left(\boldsymbol{\varepsilon}_{\boldsymbol{p}}\right)$ foi estimada através da Equação 9, que relaciona a massa específica aparente com a real. A porosidade bulk ( $\boldsymbol{\varepsilon}_{\boldsymbol{b}}$ ), ou fração de vazios do leito fixo constituídos pelos grãos, foi estimado pela Equação 10. A porosidade total do leito ( $\boldsymbol{\varepsilon}_{\boldsymbol{t}}$ ), ou frações de vazios total do leito de grãos, foi estimada pela Equação 11.

Tabela 1- Equações para o cálculo da porosidade.

\begin{tabular}{lll}
\hline Porosidade & Equação \\
\hline Partícula & $\varepsilon_{p}=1-\frac{\rho_{p}}{\rho_{s}} \quad$ (9) \\
Bulk & $\varepsilon_{b}=1-\frac{\rho_{b}}{\rho_{p}} \quad(10)$ \\
Total do leito & $\varepsilon_{t}=1-\frac{\rho_{b}}{\rho_{s}} \quad(11)$ \\
\hline
\end{tabular}

\section{RESULTADOS E DISCUSSÃO}

\subsection{Secagem em camada fina}

As curvas de secagem apresentadas nas Figuras 1 a 4 foram construídas de tal forma que fosse possível visualizar os efeitos isolados de temperatura e velocidade do ar de secagem. Nas Figuras 1 e 3, as amostras de grãos de cevada passaram pelo processo de reumidificação lenta e nas Figuras 2 e 4, as amostras passaram pelo processo de reumidificação rápida.

Verificam-se nas Figuras 1 e 2 os dados experimentais da cinética de secagem de grãos de cevada nas temperaturas de $40^{\circ} \mathrm{C}$, $45^{\circ} \mathrm{C}$ e $50^{\circ} \mathrm{C}$, expressos pela umidade adimensional em função do tempo de secagem. Observa-se na Figura 1 que o efeito da temperatura é significativo no tempo de secagem, entre 50 - 350 minutos, na redução de umidade do material. A variação de $5^{\circ} \mathrm{C}$ foi suficiente para observar a influência da temperatura na secagem do material através de diferenças visíveis entre as curvas. Já na Figura 2 o efeito da temperatura é pouco significativo. A variação de $5^{\circ} \mathrm{C}$, não foi suficiente para observar a influência da temperatura na secagem do material através de diferenças significativas entre as curvas.

Nas Figuras 3 e 4, os dados experimentais de cinética de secagem foram expressos também através da umidade adimensional em função do tempo de secagem, mas com temperatura constante e velocidades do ar de secagem de $0,8 \mathrm{~m} / \mathrm{s}$ e 4,0 $\mathrm{m} / \mathrm{s}$. Pode-se observar que a velocidade do ar de secagem não exerce influência significativa, indicando que a transferência de massa no interior dos grãos de cevada (difusão) corresponde à etapa limitante durante o processo de secagem, sendo o efeito convectivo desprezível.

Ao observar as Figuras 1 a 4 quanto à forma de reumidificação das amostras, verifica-se que os métodos de reumidificação, lenta e rápida, apresentam cinéticas de secagem diferentes. $\mathrm{O}$ método de reumidificar altera a cinética de secagem dos grãos pelo fato de que ao se realizar uma reumidificação rápida e em seguida realizar o processo de secagem, a umidade do grão é mais superficial, quando comparado a uma reumidificação lenta, em que houve tempo 
para homogeneizar a umidade no interior dos grãos.

Sendo assim, a reumidificação lenta foi a metodologia utilizada para a obtenção das umidades iniciais utilizadas na caracterização dos grãos de cevada.

Figura 1 - Dados experimentais de cinética de secagem parametrizados na temperatura do ar: reumidificação lenta.

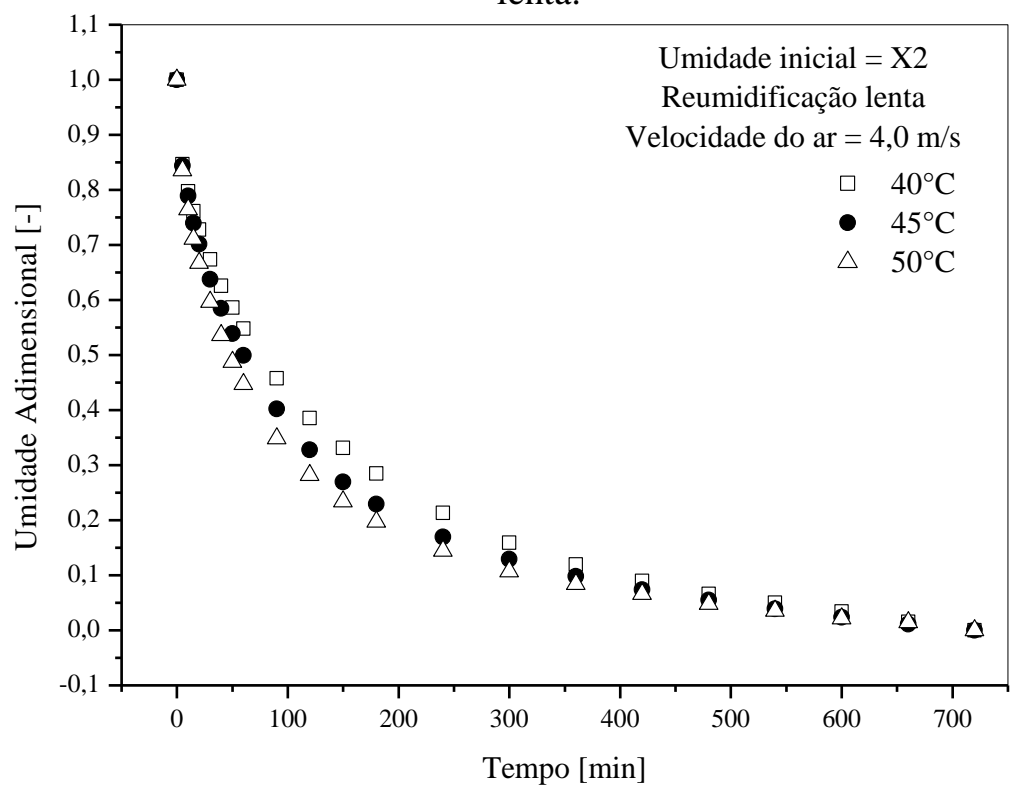

Figura 2 - Dados experimentais de cinética de secagem parametrizados na temperatura do ar: reumidificação

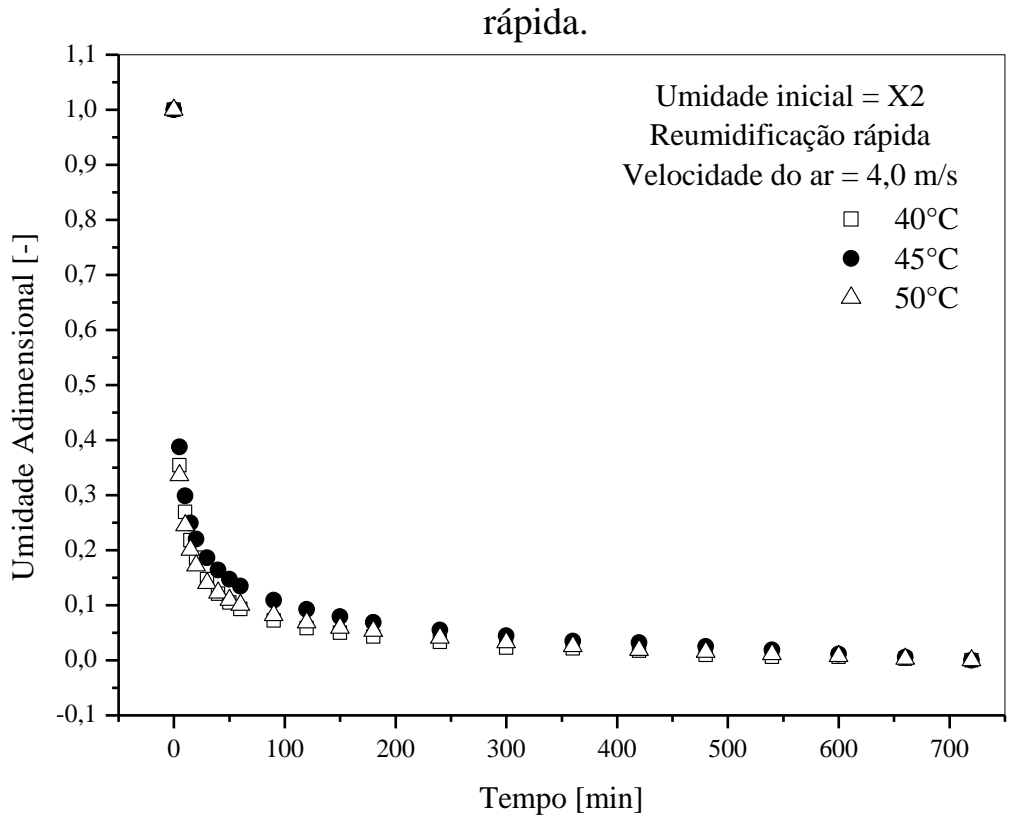


Figura 3 - Dados experimentais de cinética de secagem parametrizados na velocidade do ar: reumidificação lenta.

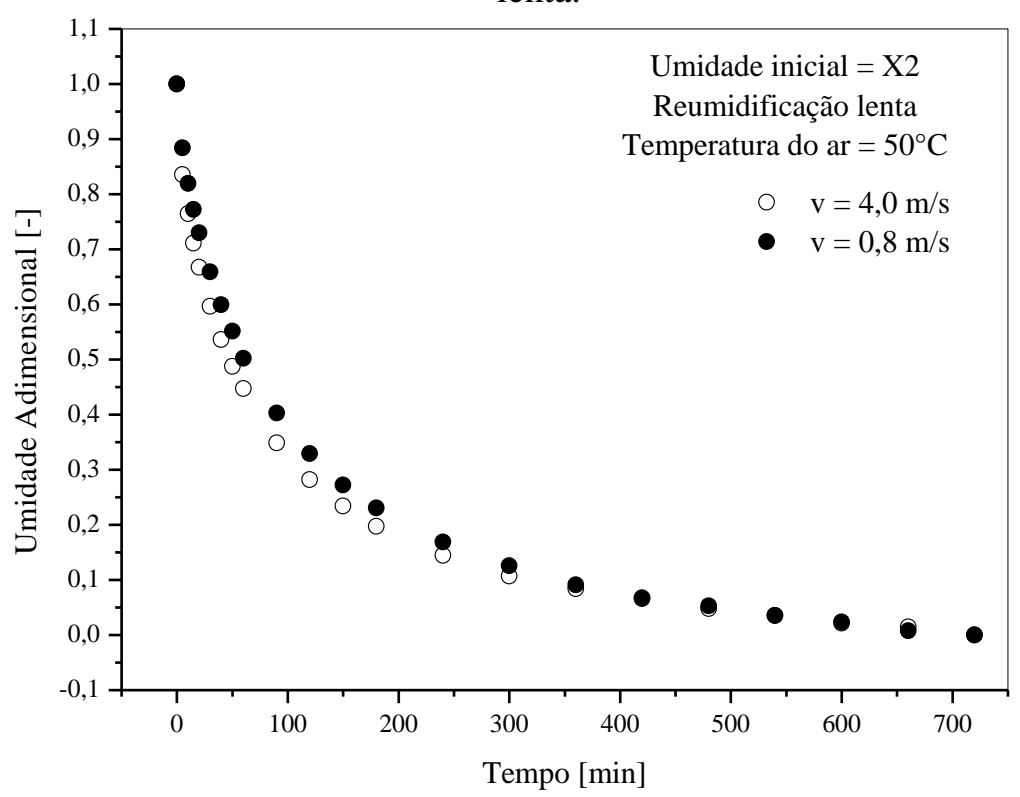

Figura 4 - Dados experimentais de cinética de secagem parametrizados na velocidade do ar: reumidificação rápida.

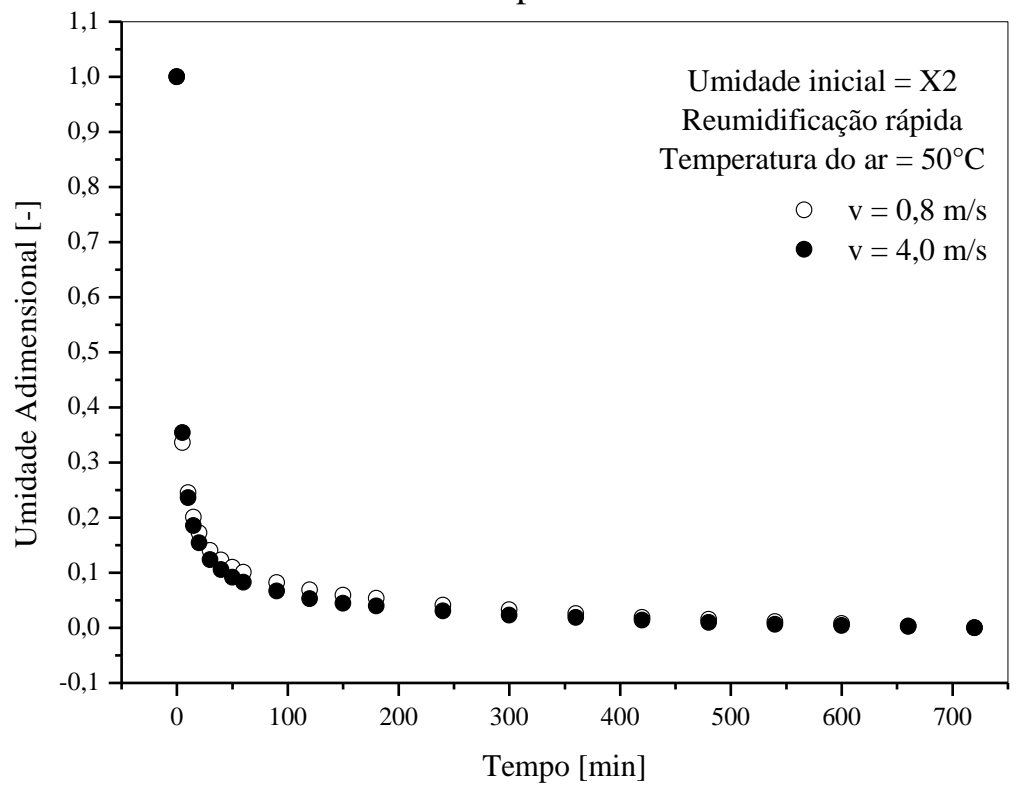

\subsection{Umidade}

Após a reumidificação lenta e utilizando o método da estufa foram realizadas as medidas de umidade dos grãos, que estão apresentados na Tabela 2.

\subsection{Análise Granulométrica}

Com os resultados das frações mássicas obtidos da distribuição granulométrica dos grãos de cevada obteve-se o histograma, apresentado na Figura 5. 
Pode-se observar que mais de $90 \%$ dos grãos, para os três conteúdos de umidade, apresentaram diâmetro maior que $2,8 \mathrm{~mm}$. O diâmetro médio de Sauter para cada conteúdo de umidade, calculado através da Equação 1, está apresentado na Tabela 2.

Segundo Kunze (2004), a classificação por tamanho é o exame físico mais importante da cevada e quando os grãos retidos na peneira acima de $2,36 \mathrm{~mm}$ representam mais de $95 \%$, estes grãos são classificados como cevada de qualidade premium.
Figura 5- Fração mássica retida em cada peneira.

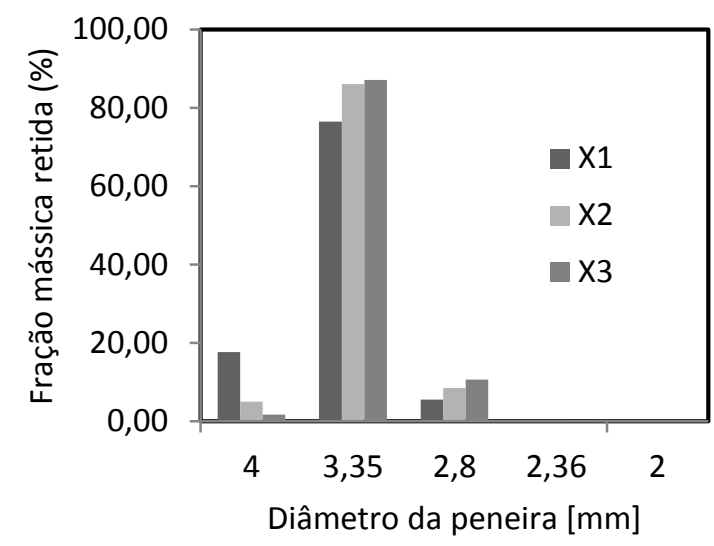

Tabela 2 - Propriedades físicas dos grãos de cevada.

\begin{tabular}{lcccc}
\hline \multicolumn{2}{c}{ Propriedades Físicas } & & \multicolumn{3}{c}{ Dados } \\
& & $\mathbf{X 1}$ & $\mathbf{X 2}$ & $\mathbf{X 3}$ \\
\hline Umidade em base úmida & $\mathrm{X}_{\mathrm{bu}}[\%]$ & $26,5 \pm 0,3$ & $21,1 \pm 0,4$ & $13,6 \pm 0,4$ \\
Umidade em base seca & $\mathrm{X}_{\mathrm{bs}}$ & $0,36 \pm 0,01$ & $0,27 \pm 0,01$ & $0,16 \pm 0,01$ \\
Diâmetro médio de Sauter & $\bar{D}[\mathrm{~mm}]$ & 3,75 & 3,65 & 3,62 \\
Comprimento & $\mathrm{L}[\mathrm{mm}]$ & $8,75 \pm 0,16$ & $8,43 \pm 0,09$ & $8,38 \pm 0,05$ \\
Largura & $\mathrm{W}[\mathrm{mm}]$ & $4,30 \pm 0,14$ & $4,06 \pm 0,16$ & $3,99 \pm 0,09$ \\
Espessura & $\mathrm{T}[\mathrm{mm}]$ & $6,70 \pm 0,13$ & $6,43 \pm 0,04$ & $6,39 \pm 0,03$ \\
Diâmetro da parte esférica & $\mathrm{B}\left[\mathrm{mm}^{2}\right]$ & $5,37 \pm 0,14$ & $5,11 \pm 0,11$ & $5,05 \pm 0,07$ \\
Área superficial & $\mathrm{S}\left[\mathrm{mm}^{2}\right]$ & $106,51 \pm 5,06$ & $97,10 \pm 2,67$ & $95,11 \pm 1,89$ \\
Volume & $\mathrm{V}\left[\mathrm{mm}^{3}\right]$ & $95,39 \pm 7,04$ & $82,72 \pm 4,00$ & $80,04 \pm 2,67$ \\
Perímetro & $\mathrm{p}\left[\mathrm{mm}^{3}\right]$ & $21,27 \pm 0,41$ & $20,49 \pm 0,10$ & $20,31 \pm 0,07$ \\
Área projetada & $\mathrm{A}\left[\mathrm{mm}^{2}\right]$ & $27,49 \pm 1,19$ & $24,82 \pm 0,85$ & $24,23 \pm 0,59$ \\
Circularidade & $\vartheta$ & $1,31 \pm 0,01$ & $1,35 \pm 0,05$ & $1,36 \pm 0,02$ \\
Esfericidade & $\phi$ & $0,76 \pm 0,01$ & $0,74 \pm 0,02$ & $0,74 \pm 0,01$ \\
Massa (1000 sementes) & $\mathrm{m}[\mathrm{g}]$ & $53,51 \pm 0,45$ & $50,45 \pm 0,37$ & $46,89 \pm 0,19$ \\
Volume (1000 sementes) & $\mathrm{V}\left[\mathrm{cm}^{3}\right]$ & $77 \pm 2$ & $72 \pm 2$ & $65 \pm 1$ \\
Massa específica real & $\rho_{\mathrm{s}}\left[\mathrm{g} / \mathrm{cm}^{3}\right]$ & $1,337 \pm 0,006$ & $1,345 \pm 0,003$ & $1,371 \pm 0,001$ \\
Massa específica aparente & $\rho_{\mathrm{p}}\left[\mathrm{g} / \mathrm{cm}^{3}\right]$ & $1,220 \pm 0,002$ & $1,229 \pm 0,002$ & $1,261 \pm 0,004$ \\
Densidade do leito (bulk) & $\rho_{\mathrm{b}}\left[\mathrm{g} / \mathrm{cm}^{3}\right]$ & $0,701 \pm 0,006$ & $0,718 \pm 0,001$ & $0,750 \pm 0,001$ \\
Porosidade da partícula & $\varepsilon_{\mathrm{s}}$ & $0,088 \pm 0,008$ & $0,086 \pm 0,002$ & $0,080 \pm 0,008$ \\
Porosidade do leito (bulk) & $\varepsilon_{\mathrm{b}}$ & $0,425 \pm 0,005$ & $0,416 \pm 0,001$ & $0,405 \pm 0,002$ \\
Porosidade total & $\varepsilon_{\mathrm{t}}$ & $0,476 \pm 0,007$ & $0,466 \pm 0,001$ & $0,453 \pm 0,001$ \\
\hline
\end{tabular}

\subsection{Análise de Imagens}

De acordo com os dados experimentais referentes às análises de imagem e as propriedades calculadas pelas Equações 2 a 5, que estão apresentadas na Tabela 2. Pode-se observar uma leve tendência de aumento das dimensões com o aumento da umidade. Essas propriedades apresentaram uma variação de $4,5 \%, 7,9 \%, 4,8 \%$ e $6,3 \%$ entre a maior e a menor medida, para o comprimento, largura, 
espessura e diâmetro da parte esférica, respectivamente.

Para as medidas de área projetada apresentadas na Tabela 2, obtida por análise de imagens, em função da umidade, observase uma tendência de aumento de 13,5\%.

Com os valores da área superficial, calculada pela Equação 4, em função da umidade comprova-se um aumento da área superficial com o aumento da umidade, uma variação de $12,0 \%$ entre a menor e a maior medida.

Para as medidas do perímetro, obtido por análise de imagem, em função da umidade, houve uma variação de 4,7\% nesta medida.

As medidas do volume, calculado pela Equação 3, em função da umidade indica que há uma tendência de aumento do volume com a umidade, uma variação de $19,2 \%$ entre a menor e a maior medida é observada.

$\mathrm{Na}$ faixa de umidade estudada, 0,36 (bs) a 0,16 (bs), foi aplicado o teste $\mathrm{t}$ de Student com nível de significância de $5 \%$ para as medidas obtidas por análise de imagens como o comprimento, espessura, perímetro e circularidade, e os resultados não apresentaram variação significativa. Houve diferença significativa entre as médias das medidas de largura e área. Para as medidas calculadas a partir das medidas obtidas pela análise de imagens, há diferença significativa entre os valores do diâmetro da parte esférica, área superficial e volume para as comparações entre X1(0,36 bs) e X3(0,16 bs).

A circularidade foi calculada pela técnica de análise de imagens. Observa-se uma redução de $3,7 \%$ nas medidas obtidas. A esfericidade foi calculada pela Equação 5. Observa-se pouca variação da esfericidade, $2,7 \%$. Os testes $\mathrm{t}$, aplicados as medidas de circularidade e esfericidade mostraram que não há diferença significativa entre as medidas. Os fatores de forma permaneceram praticamente constantes com o aumento da umidade. Estes resultados indicam que o aumento das dimensões foi proporcional, resultando em variação desprezível na forma das sementes. Fato também observado por Arnosti Jr. (1997) para sementes de gramíneas e por Pereira (2010) para sementes de painço.

\subsection{Massa e volume de 1000 grãos de cevada}

Os valores da massa e do volume de 1000 grãos de cevada em função da umidade estão apresentados na Tabela 2. Observa-se um aumento linear de $14,1 \%$ da massa com a umidade e para o volume de 1000 grãos de cevada observa-se um aumento linear de $18,6 \%$ para a faixa de umidade de estudada.

Há um aumento nos valores da massa e volume de 1000 grãos de cevada com o aumento da umidade e foi confirmado pelo teste $\mathrm{t}$ de Student que a diferença entre as médias das medidas é significativa.

\subsection{Medidas de massa específica, densidade do leito (bulk) e porosidades}

Observando os dados de massa específica real, massa específica aparente e densidade do leito (bulk), apresentados na Tabela 2, observa-se que os valores destas medidas aumentam com a diminuição da umidade.

Os valores da massa específica aparente e massa específica real diminuem com o aumento da umidade dos grãos. Brooker et al. (1992) afirma que a massa específica aparente de grãos agrícolas diminui com o aumento da umidade do produto. E Brusewitz (1975), investigando diversos grãos reumidificados, também constatou que os valores da massa específica real decresceram com o aumento da umidade do produto.

Ao aplicar o teste $\mathrm{t}$ de Student com nível de 5\% de significância para os grupos de medidas referentes as massas específicas, os testes t de Student confirmam que houve diferença significativa entre as médias das 
medidas. Apenas para as medidas de massa específica real entre X1 e X2 não houve diferença significativa entre as médias das medidas. Para as medidas da porosidade da partícula, bulk e total, o teste $\mathrm{t}$ de Student confirma que não há diferença entre as médias da porosidade das partículas. Já para a porosidade bulk e total há diferença entre as médias, apenas quando comparamos X2(0,27 bs) e $\mathrm{X} 3(0,16$ bs) não há diferença entre as médias.

\section{CONCLUSÃO}

O método de reumidificar altera a cinética de secagem dos grãos, pois ao realizar uma reumidificação rápida e em seguida realizar o processo de secagem, a umidade do grão é mais superficial, quando comparado a uma reumidificação lenta, em que houve tempo para homogeneizar a umidade no interior dos grãos.

Considerando o encolhimento um fenômeno físico caracterizado pela contração de volume do material durante o processo de secagem, após a análise das propriedades físicas apresentadas, pode-se afirmar que os grãos de cevada sofrem encolhimento.

Com a análise de imagens foram obtidos dados individuais dos grãos de cevada, que apesar da pouca variação observada para as dimensões lineares, como descritas anteriormente, as variações tornamse mais significativas quando foram calculadas áreas e volumes, o que pode ser explicado matematicamente, já que a área e o volume são obtidos, respectivamente, pelo quadrado ou cubo das dimensões lineares.

Observou-se também a diminuição da massa específica real, massa específica aparente e densidade bulk, com o aumento da umidade. Este fato ocorre devido, principalmente, ao maior aumento no volume dos grãos em comparação com o aumento de massa dos grãos (TAVAKOLI et al., 2009).

\section{NOMENCLATURA}

\author{
$\mathrm{A}$ - área projetada $\left[\mathrm{mm}^{2}\right]$ \\ B - diâmetro da parte esférica [mm] \\ Di - abertura da peneira i [mm] \\ $\bar{D}$ - diâmetro de Sauter [mm] \\ L' - comprimento [mm] \\ $\mathrm{T}^{\prime}$ - espessura $[\mathrm{mm}]$ \\ $\mathrm{V}$ - volume $\left[\mathrm{mm}^{3}\right]$ \\ $\mathrm{W}$ - largura [mm] \\ $\mathrm{S}$ - área superficial $\left[\mathrm{mm}^{2}\right]$ \\ $\phi$ - esfericidade \\ $\vartheta$ - circularidade \\ $\varepsilon_{\mathrm{b}}$ - porosidade bulk \\ $\varepsilon_{\mathrm{p}}$ - porosidade da partícula \\ $\varepsilon_{\mathrm{t}}$ - porosidade total do leito \\ $\rho_{\mathrm{p}}-$ massa específica aparente $\left[\mathrm{g} / \mathrm{cm}^{3}\right]$ \\ $\rho_{\mathrm{s}}-$ massa específica real $\left[\mathrm{g} / \mathrm{cm}^{3}\right]$ \\ $\rho_{\mathrm{b}}$ - densidade bulk $\left[\mathrm{g} / \mathrm{cm}^{3}\right]$ \\ xi - fração mássica retida \\ $\mathrm{T}_{\mathrm{g}}$ - temperatura do ar de secagem \\ $\mathrm{v}_{\mathrm{g}}$ - velocidade do ar de secagem \\ UR - umidade relativa \\ $\mathrm{X}_{0}$ - umidade inicial (\%, base úmida)
}

\section{REFERÊNCIAS}

ARNOSTI JR, S. Desenvolvimento de um secador transportador do tipo esteira com escoamento cruzado e caracterização de sementes de gramíneas. 1997. 232 p. Tese (Doutorado em Engenharia Química) Departamento de Engenharia Química, Universidade Federal de São Carlos, São Carlos, SP, 1997.

ASSOCIATION OF OFFICIAL ANALYTICAL CHEMISTS (AOAC). Official methods of analysis of the Association of Official Analytical Chemists. 17 ed. Gaithersburg, Maryland: AOAC, 2002, Vol. 2.

BRASIL. Embrapa Trigo. Cevada. Disponível em: <http:// 
www.cnpt.embrapa.br/culturas/cevada>.

Acesso em: 08 out. 2013.

BRIGGS, D. E., BOULTON, C. A., BROOKES, P. A., STEVES, R. Brewing: Science and Practice. New York: CRC Press, 2004.

BROOKER, D. B., BAKKER-ARKEMA, F.W., HALL, C.W. Drying and Storage of Grains and Oilseeds. New York: Van Nostrand Reinhold, 1992, p. 450.

BRUSEWITZ, G. H. Density of rewetted high moisture grains. Transactions of the ASAE. St. Joseph, Vol. 18, n. 5, p. 935-938, 1975.

FUMAGALLI, F. Estudo da secagem das sementes de Brachiaria brizantha. 2007. 149 p. Tese (Doutorado em Engenharia Química) - Departamento de Engenharia Química, Universidade Federal de São Carlos, São Carlos, SP, 2007.

KUNZE, W. Technology Brewing and Malting. Berlin: Versuchs und Lehranstalt für Brauerei in Berlin (VLB). 2004.

McMinN, W. A., MAGEE, T. R. A. Principles, Methods and Applications of the convective drying of foodstuffs. Trans IChemE. Part C. 1999. p. 175-193.

MOHSENIN, N. N. Physical Properties of plant and animal materials: structure, physical characteristics and mechanical properties. New York: Gordon and Breach Scientific Publishers, 1970. p. 734.

PEREIRA, A. V. Caracterização e secagem de sementes de painço (Setaria italica L.). 2010. 92 p. Dissertação (Mestrado em Engenharia Química) - Departamento de Engenharia Química, Universidade Federal de São Carlos, São Carlos, SP, 2010.
TAVAKOLI, $\quad$ M.; TAVAKOLI, H.; RAJABIPOUR, A.; AHMADI, H.; GHARIBZAHEDI, S. M. T. Moisture-dependent physical properties of barley grains. International Journal of Agricultural and Biological Engineering, 2009, Vol. 2, n. 4, p. $84-91$.

TUNES, L. M. de; BARROS, A. C. S. A.; BADINELLI, P. G.; GARCIA, D. C. Diferentes épocas de colheita e qualidade fisiológica de sementes de cevada. Revista Brasileira de Sementes. Vol. 32, n. 2, p. 042048, 2010.

VIEIRA, G. N. A. Caracterização e secagem de grãos de linhaça marrom (Linum usitatissimum $L$.) em leito fixo e fluidizado. 2012. 82 p. Dissertação (Mestrado em Engenharia Química) - Departamento de Engenharia Química, Universidade Federal de São Carlos, São Carlos, SP, 2012.

ZOTIN, F. M. Z. Efeito de parede em colunas de recheio. $1985.85 p$. Dissertação (Mestrado em Engenharia Química) Departamento de Engenharia Química, Universidade Federal de São Carlos, São Carlos, SP, 1985.

\section{AGRADECIMENTOS}

Ao Programa de Pós-Graduação em Engenharia Química (PPGEQ - UFSCar), ao Conselho Nacional de Desenvolvimento Científico e Tecnológico (CNPq) e à Coordenação de Aperfeiçoamento de Pessoal de Nível Superior (CAPES) pelo apoio financeiro essencial para o desenvolvimento deste trabalho. 